\title{
Principles for Insurance Regulation: An Evaluation of Current Practices and Potential Reforms
}

\author{
Robert W. Klein \\ Department of Risk Management and Insurance Research, Georgia State University, P.O. Box 4036, \\ Atlanta, GA 30302-4036, U.S.A.
}

The recent financial crisis and its cascading effects on the global economy have drawn increased attention to the regulation of financial institutions including insurance companies. While many observers would argue that insurance companies were not significant contributors to the crisis, the role of insurance companies in the financial economy and their potential vulnerability to systemic risk have become matters of considerable interest to policy-makers and regulators. In this context, this paper examines the basic economic principles that should govern the regulation of insurance and employs these principles in assessing current regulatory practices and potential reforms. Specifically, it articulates the basic rationale for insurance regulation, which is the remediation of market failures where regulation can enhance social welfare. In insurance, the principal market failures that warrant regulatory intervention are severe asymmetric information problems and principalagent conflicts that could lead some insurance companies to incur excessive financial risk and/or engage in abusive market practices that harm consumers. This provides an economic basis for the regulation of insurers' financial condition and market conduct. At the same time, the regulatory measures that are employed to correct market failures should be efficient and effective. Judged against these principles, the systems for solvency and market conduct regulation in the United States warrant significant improvement. There appears to be little or no justification for regulating insurance rates in competitive markets and the states should move forward with full deregulation of insurance prices. The EU appears to be much farther ahead in terms of implementing best practices in the regulation of insurers' financial condition under its Solvency II initiative. It is also much closer to the desirable goal of full price deregulation than the United States.

The Geneva Papers (2012) 37, 175-199. doi:10.1057/gpp.2011.9;

published online 5 October 2011

Keywords: insurance regulation; market failures; Solvency II

\section{Introduction}

The recent financial crisis and its cascading effects on the global economy have drawn increased attention to the regulation of financial institutions including insurance companies. While many observers would argue that insurance companies were not significant contributors to the crisis, they did feel its effects, particularly in the life sector. $^{1,2}$ A number of life insurers were stressed because of their investments in

\footnotetext{
${ }^{1}$ See Wang et al. (2009).

${ }^{2}$ The American International Group (AIG) received prominent attention because of its losses on credit
} 
mortgage-backed securities and other real estate-related assets. ${ }^{3}$ As the crisis triggered a severe economic recession and a precipitous fall in stock prices, both life and non-life insurers suffered further asset losses. Some took advantage of government programmes to bolster their capital. Fortunately, these developments did not trigger a wave of insurer insolvencies. Nonetheless, the role of insurance companies in the financial economy and their potential vulnerability to systemic risk have become matters of considerable interest to policy-makers and regulators.

In this context, this paper examines the basic economic principles that should govern the regulation of insurance, and employs these principles in assessing current regulatory practices and potential reforms. This assessment is particularly timely as policy-makers review and restructure the framework for the regulation of financial institutions. It should be noted that insurance regulatory reform has been an ongoing process with initiatives that began before 2008. Still, the recent financial crisis has created a heightened sense of urgency regarding reform and added new issues for policy-makers to consider. Various stakeholders have a vested interest in this process and reasons to advocate for reforms that are economically sound and that will promote viable and efficient insurance markets.

This paper reviews fundamental principles of insurance regulation that should be applicable in various jurisdictions and assesses current practices and potential reforms in light of these principles. The paper is organised as follows. The section "Economic principles for insurance regulation" outlines the basic rationale for the regulation of insurance and the economic principles that can be derived from this rationale. Several key areas of insurance regulation are addressed including solvency, prices and market conduct, with particular emphasis on financial (i.e., solvency) regulation. The section "Evaluation of current practices and potential reforms" then applies these principles in assessing the soundness and efficiency of current regulatory practices and considering how these practices might be improved. This assessment focuses primarily on insurance regulation in the United States with some extension to the European Union (EU) and other countries. The final section summarises and concludes.

\section{Economic principles for insurance regulation}

\section{Why insurance should be regulated}

The economic foundation for regulation is based on the presence of market failures. ${ }^{4}$ These market failures are judged against the social welfare maximising conditions for perfect competition. Perfect competition requires numerous buyers and sellers in a

default swaps due to the activities of its investment subsidiaries and not its insurance operations. Some insurance companies, including insurers affiliated with AIG, did suffer losses from their securities lending activities. In addition, financial guaranty insurers suffered severe losses due to their issuance of credit default swaps and mortgage insurance. In Europe, Swiss Re suffered significant write-downs in the value of its assets due to its issuance of credit default swaps and investments in mortgage-backed securities.

${ }^{3}$ A number of life insurers were also "squeezed" by lower returns on their investments and the guarantees embedded in their variable annuity products.

${ }^{4}$ See, for example, Spulber (1989), Viscusi et al. (2000). 
market, the lack of barriers to entry and exit, perfect information, and a homogenous product. Under these conditions, the joint surplus or gains from trade of producers and consumers is maximised. Of course, few if any markets satisfy the conditions for perfect competition in the real world. Hence, in assessing the need for and benefits of regulation in an imperfect world, markets are often judged against a standard of "workable competition" that reasonably approximates the conditions for perfect competition to the degree that government intervention cannot improve social welfare. ${ }^{5}$ This standard of workable competition has the desirable attribute of focusing attention on the presence of market failures wherein government remedies can improve market efficiency and enhance social welfare.

Potential market failures in insurance include severe asymmetric information problems and principal-agent conflicts that could lead some insurance companies to incur excessive financial risk and/or engage in abusive market practices that harm consumers. Insurance consumers, particularly individuals and households, face significant challenges in judging the financial risk of insurers and properly understanding the terms of insurance contracts. There is also the possibility that insurers could acquire sufficient market power to restrict competition, resulting in barriers to entry, higher prices and excess profits.

The issue of systemic risk has garnered considerable attention due to the recent financial crisis. Systemic risk could be defined as the risk that a market or financial system could experience severe instability, potentially catastrophic, caused by idiosyncratic events or conditions in financial intermediaries. It arises from the links between firms in a system or market in which the failure of one or more firms can have cascading effects that could potentially bring down an entire system or market. ${ }^{6}$ Arguably, this is a kind of market failure that can arise from excessive risk-taking by financial institutions whose failure can lead to the failure of other firms in a market or system.

In contrast to market failures, there are a set of circumstances that could be termed "market problems". These are not failures in the economic sense but constitute "undesirable" market outcomes, for example high prices, the unavailability of insurance coverage, etc., that result from conditions affecting the cost of risk, rather than violations of the conditions for perfect or workable competition. For example, in some markets insurance may be expensive because claim costs are high. One would expect the price of insurance to be commensurate with expected claim costs. While this may cause hardships for consumers, it is a natural result of properly functioning market forces and not a condition that can be remedied by regulation per se.

This kind of situation can be contrasted with true market failures in which there is a significant violation of the conditions for workable competition. The rationale for government intervention when market failures occur is based on promoting or restoring economic efficiency. For example, an insurer may take on too much financial risk because its owners would not be required to pay the full costs of its insolvency due to limited liability of the corporate form of the organisation. In many industries, the

\footnotetext{
${ }^{5}$ Scherer and Ross (1990).

${ }^{6}$ See "Systemic Risk" at www.en.wikipedia.org/wiki/Systemic_risk\#cite_note-2.
} 
creditors of firms may be able to sufficiently judge the firms' financial risk and take steps to protect their interests. However, the circumstances for certain financial institutions such as banks and insurance companies are arguably more problematic for creditors. One could make the case that the costs of monitoring are so high for consumers that it is cheaper for the government to undertake this task and take action against insurers that incur excessive financial risk. If it is more efficient for the government to perform this monitoring and employ other compliance/enforcement measures, then regulatory intervention could increase social welfare.

Similarly, if there is collusion among insurers due to market power resulting from the presence of a small number of firms and entry/exit barriers in a particular market, then the government could remedy this market failure through antitrust measures or regulating prices. The assumption here is that the government would ensure that the prices charged would be same as those that would be set in a competitive market. This is an efficiency-based argument that implies that the regulator would attempt to enforce prices equal to marginal costs. If, in contrast, high insurance prices are due to high levels of risk (and not collusion among insurers) then regulation cannot enforce lower prices without causing market distortions. This distinction is important because regulatory intervention and policies often can be motivated by the desire to "fix" or ameliorate market problems rather than remedy legitimate market failures.

Optimal regulation is based upon an ideal set of policies that attempt to replicate the conditions of a competitive market and maximise social welfare. This theoretical model of regulation is based on the premise that regulators seek to remedy market failures and not market problems caused by other external factors. This may include failures that would otherwise cause insurers to incur an excessive risk of insolvency and/or engage in abusive trade practices, for example, misrepresenting insurance products, refusing to pay legitimate claims, etc. This assumes that regulators have perfect information and can determine and implement the correct market solutions, an assumption that may not be valid under some circumstances. Hence, not all market failures can necessarily be remedied by regulation, and the desirability of any particular regulatory intervention must be assessed in terms of regulators' ability to remedy a specified market failure and any deadweight costs associated with regulatory intervention that may exceed the benefits from intervention. Further, this line of reasoning presumes that regulators will employ "best practices" and the most efficient measures to address market failures.

\section{Solvency regulation}

The social welfare argument for the regulation of insurer solvency derives from inefficiencies created by costly information and principal-agent problems. ${ }^{7,8}$ Owners of

\footnotetext{
${ }^{7}$ Munch and Smallwood (1981).

${ }^{8}$ Costly information refers to the fact that it is costly for consumers to acquire information about the financial condition of an insurer and the relative value of its products in relation to their prices. Principal-agent problems refer to the difficulty that a consumer (the principal) faces in monitoring and controlling the activities and financial risk of an insurer (the agent), once the consumer has signed a contract with the insurer and paid premiums for coverage of future claims and benefit obligations.
} 
insurance companies have diminished incentives to maintain a high level of safety to the extent that their personal assets are not at risk for unfunded obligations to policy-holders that would arise from insolvency. The argument is that it is costly for consumers to properly assess an insurer's financial strength in relation to its prices and quality of service. ${ }^{9}$ Insurers also can increase their risk after policy-holders have purchased a policy and paid premiums - a "principal-agent" problem that may be very costly and difficult for policy-holders to control.

There are other aspects of excessive insolvency risk that may motivate regulatory intervention. Financial regulators are also concerned about "contagion" and the possibility that a spike in insurer insolvencies could induce a "crisis of confidence" that may have negative effects on the industry. Further, there may be negative externalities associated with excessive insurer insolvency risk as the costs of unpaid claims may be shifted beyond policy-holders to their creditors. Hence, it is common for the regulation of financial institutions to be coupled with some form of insolvency guarantees (e.g., deposit insurance, insurance guaranty associations, etc.) that cover at least a portion of the obligations of bankrupt firms. Note, this phenomenon does not constitute systemic risk as defined above but does reflect the negative externalities associated with the failure of one or more insurance companies.

Arguably, the goal of optimal insurance solvency regulation should not be to minimise insolvencies as the costs of achieving such a goal would likely exceed the perceived benefits. A more reasonable goal would be to minimise or limit the social cost of insurer insolvency within acceptable parameters. The social cost is more than the lost equity of the insurer as it includes the effects on policy-holders and third parties who may be creditors of insurers. Regulators can potentially limit insolvency risk by requiring insurers to meet a set of financial standards and taking appropriate actions if an insurer assumes excessive default risk or experiences financial distress. ${ }^{10}$

\section{Price regulation}

There are two potential rationales for regulation of insurance prices. The traditional explanation for regulation of insurance prices involves costly information and solvency concerns. ${ }^{11}$ According to this explanation, insurers' incentive to incur excessive financial risk and even engage in "go-for-broke" strategies may result in inadequate prices. Some consumers might buy insurance from carriers charging inadequate prices without properly considering the greater financial risk involved. In this scenario, poor incentives for solvency safety could induce a wave of "destructive competition" in which all insurers are forced to cut their prices below costs to retain their market

\footnotetext{
${ }^{9}$ The costs of determining financial soundness are much lower today than they were in the past, as anyone with knowledge and access to the Internet can check an insurer's claims paying ability - provided by rating agencies - on the Internet. However, rating agencies cannot engage in enforcement actions (although they may pressure insurers to correct problems) and most countries do not accept the notion that they are an adequate substitute for government regulation.

${ }^{10}$ See, for example, Cummins et al. (1995).

11 Joskow (1973), Hanson et al. (1974).
} 
180

positions. ${ }^{12}$ In the United States, the solution offered was uniform prices developed by industry-rating organisations subject to regulatory oversight to prevent excessive prices.

This view essentially governed the regulation of property-casualty insurance prices in the United States until the 1960s, when states began to disapprove or reduce price increases in lines such as personal auto and workers' compensation insurance. The rationale that some might offer for government restrictions on insurance price increases is that consumer search costs impede competition and lead to excessive prices and profits. ${ }^{13}$ It also might be argued that it is costly for insurers to ascertain consumers' risk characteristics accurately, giving an informational advantage to insurers already entrenched in a market and creating barriers to entry that diminish competition. According to this view, the objective of regulation is to enforce a ceiling that will prevent prices from rising above a competitive level and enabling insurers to earn excess profits.

In addition, the public may express a preference for regulatory policies to lower or cap insurance prices consistent with social norms or objectives. This may not justify insurance price regulation based on the principles asserted above but, nonetheless, explains why insurance prices are regulated in some circumstances when a pure economic justification is not apparent. These circumstances may include government mandates that compel consumers or firms to secure certain types of insurance.

However, the empirical evidence does not tend to support a case for the regulation of insurance prices in most markets in developed countries where the insurance industry is relatively mature. For example, studies of insurance markets in the United States indicate that they are highly competitive in terms of their structure and performance. ${ }^{14}$ Entry barriers tend to be low and concentration levels rarely approach a point that would raise concerns about insurers' market power.

Further support for this assertion is provided by Table 1, which shows the number of insurers and concentration levels in major lines of business in the non-life sector in the United States in 2006. In excess of 1,270 insurer groups (including stand-alone companies) sold property-casualty insurance in 2006, with several hundred insurers competing in each major line. The principal measures of market concentration, the ten-firm concentration ratio (CR10), which is the market share of the top ten insurers, and the Herfindahl-Hirschman Index (HHI), which is the sum of the squared market shares of all insurers, also indicate competitive market structures in these lines. The top ten insurers accounted for less than 65 per cent of the premiums written in any given line and 40-50 per cent in many lines. Similarly, HHI values ranged from 255 to 784, with most lines falling between 300 and 500. These levels of concentration are considerably below levels that most economists consider necessary for firms to begin acquiring market power. ${ }^{15}$ Further, profits in both the life and non-life sectors in the

${ }^{12}$ This view likely stems from the periodic price wars (and subsequent insurer failures) that afflicted property-casualty insurance markets in the United States during the 1800s and early 1900s.

${ }^{13}$ Harrington (1992) explains but does not advocate this view. Further, the cost of shopping for insurance has dropped dramatically for personal lines of coverage (see Brown and Goolsbee, 2002).

${ }^{14}$ Cummins and Weiss (1991), Klein (1995, 2005) and Grace and Klein (2007).

${ }^{15}$ According to the Department of Justice and Federal Trade Commission 2010 Horizontal Merger Guidelines, a market with an HHI below 1,500 is considered to be "unconcentrated". 
Table 1 Property-casualty insurance market structure in the United States: 2006

\begin{tabular}{lcccccc}
\hline Line & $\begin{array}{c}\text { Number of } \\
\text { insurers }\end{array}$ & $\begin{array}{c}\text { Pct. of sector } \\
\text { DPW }(\%)\end{array}$ & CR10 (\%) & HHI & Since 1997 \\
\cline { 5 - 6 } & & & & & Entries (\%) & Exits (\%) \\
\hline Personal auto & 389 & 33.2 & 64.1 & 651 & 29.4 & 48.9 \\
Commercial auto & 389 & 6.2 & 44.4 & 272 & 33.4 & 46.2 \\
Homeowners & 438 & 12.3 & 64.2 & 784 & 27.9 & 41.2 \\
Fire \& allied & 544 & 4.2 & 53.7 & 502 & 24.8 & 41.6 \\
Commercial MP & 365 & 7.4 & 49.0 & 318 & 24.1 & 45.6 \\
General liability & 697 & 12.2 & 57.7 & 595 & 36.8 & 42.8 \\
Medical malpractice & 225 & 2.5 & 45.8 & 295 & 112.4 & 57.2 \\
Workers' compensation & 312 & 9.5 & 54.2 & 487 & 32.1 & 48.0 \\
Other & 715 & 20.0 & 43.1 & 255 & 26.2 & 45.8 \\
All lines Combined & 1,270 & 100.0 & 48.6 & 318 & 43.5 & 43.4
\end{tabular}

DPW: Direct Premiums Written; CR10: combined market share of the top ten firms; HHI: HerfindahlHirschman Index.

Source: National Association of Insurance Commissioners (NAIC) and author's calculations.

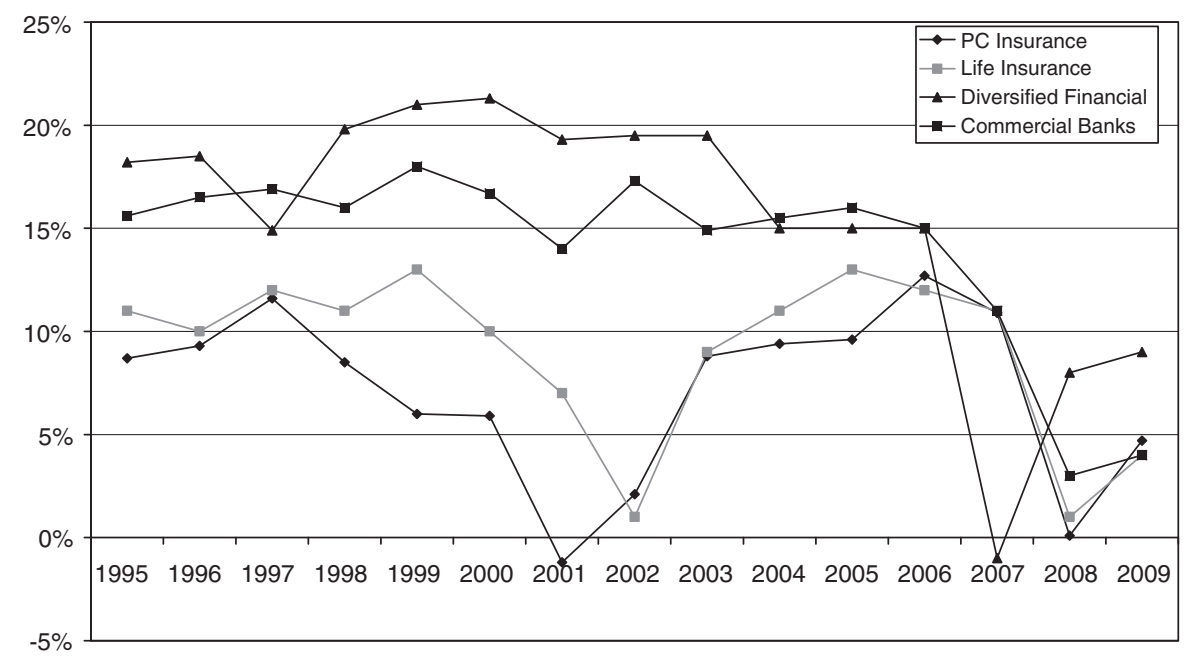

Figure 1. Annual rate of return net income as percentage of equity: 1995-2009. Source: Insurance Information Institute.

United Sectors tend to be in line with or below the rates of return earned in other industries as shown in Figure 1.

Over the last 50 years, the enforcement of uniform rates has eroded in the United States and industry organisations have moved to the promulgation of "advisory" rates or loss costs. This has caused insurer pricing to be much more independent and differentiated. Hence, it is not surprising that studies of the effects of the regulation of 
182

insurance rates have not uncovered significant benefits to consumers from such regulation. $^{16}$

In the United States, prices/premiums for life insurance and annuity products have generally not been subject to direct regulation. Price regulation in the life sector is imposed indirectly through the regulation of life insurance and annuity products. In approving such products, regulators consider whether the premiums charged according to these contracts are commensurate with the benefits offered. In health insurance, almost all the states impose some form of rating constraints in the small group market but only 19 states impose rating constraints in the individual market. ${ }^{17}$

\section{Market conduct regulation}

A stronger case can be made for regulating certain insurer market practices, such as product design, marketing and claims adjustment. Constraints on consumer choice and unequal bargaining power between insurers and consumers, combined with inadequate consumer information, can make some consumers vulnerable to abusive marketing and claims practices of insurers and their agents. ${ }^{18}$ In the United States, there have been numerous instances in which insurance products have been misrepresented and insurers or their agents have been found guilty of sales abuses. For example, a number of life insurers settled legal suits in the late 1980s and early 1990s for agent practices that took customers out of safe policies and put them in inappropriate (high risk) policies. ${ }^{19}$ Although several prominent insurers were involved in some of these cases, the greater threat probably lies with firms or agents that are not highly motivated to establish and maintain a strong reputation for fair dealings with consumers. Hence, regulators need to be especially vigilant for "bad actors" who seek gains from abusive or fraudulent transactions. The industry has taken steps to mitigate market conduct problems through self-compliance measures and the establishment of a voluntary self-regulatory organisation (SRO). At the same time, regulators have promulgated new rules and bolstered their monitoring mechanisms. ${ }^{20}$

${ }^{16}$ See, for example, Harrington (2002).

17 NAIC (2011).

${ }^{18}$ It is true that consumers subject to unfair treatment might seek remedies through the courts and sometimes do so. However, legal remedies may not be feasible for consumers with limited resources and bills to pay. In addition, it may be difficult to secure financial damages from some fraudulent insurers.

${ }^{19}$ It is interesting to note that the suspect sales practices were not discovered by regulators until after the initial lawsuits were brought. Some might view this as a regulatory failure but it also underscores the issue of regulators' capacity to proactively uncover and remedy certain market conduct problems.

${ }^{20}$ See Klein (2005) for a more detailed discussion of regulatory efforts to better police marketing and sales activities. The challenge faced by regulators is that rules tend to be somewhat arbitrary and cannot fully accommodate the variety of circumstances encountered in insurance transactions. Further, monitoring compliance with such rules can be difficult and costly given the large volume of transactions. 


\section{An optimal regulatory framework}

In sum, optimal regulation should be designed to minimise the cost of insurer insolvencies, promote the pricing of insurance at marginal cost, promote reasonable trade practices, provide appropriate incentives for insurers to police their own practices and those of their agents, and provide the optimal amount of insurance. However, optimal regulation depends upon more than just the approach to regulation. It also depends upon where regulatory authority resides or how it is apportioned among different regulatory jurisdictions and coordinated among those jurisdictions.

The United States is somewhat unique in that insurance regulation has been primarily delegated to the states. In most countries, insurance is regulated at the national level and in a few (e.g., Canada and Australia) regulatory responsibilities are divided between the states/provinces and the national government. ${ }^{21}$ In the United States, the National Association of Insurance Commissioners (NAIC) serves as the primarily vehicle for coordinating regulatory policies among the states. The EU constitutes a special case in which there is a formal legal framework designed to establish a common set of standards and harmonise the insurance regulations of its member countries. At an international level, there are advisory organisations (such as the International Association of Insurance Supervisors) that seek to harmonise insurance regulation at a global level through the promulgation of core standards and principles.

The state-based system of insurance regulation in the United States has come under heavy criticism because of the inefficiencies it creates and the additional costs it imposes on insurance transactions across state borders. ${ }^{22}$ Large insurers have pushed for the creation of an optional federal charter (OFC) that would allow insurers and agents to choose to be subject to federal regulation and exempt from state regulation. Despite strong opposition from the states and small insurers, the OFC proposal received serious consideration by the Congress until the recent financial crisis refocused its attention on federal regulation of other financial institutions. The Congress is likely to remain preoccupied with reforming the overall structure for the regulation of financial institutions and essentially leave insurance "on hold" for some period of time with some limited exceptions. ${ }^{23}$ However, it is reasonable to expect that policy-makers will revisit proposals for the federal insurance regulation as issues concerning the regulation of other financial institutions are resolved and a new financial regulatory framework is established.

\footnotetext{
${ }^{21}$ In these countries, solvency regulation is handled at the national level and market conduct regulation is delegated to the states or provinces.

${ }^{22}$ Grace and Klein (2009), Pottier (2011).

${ }^{23}$ In 2010, a Federal Insurance Office was established as one of the provisions of the Dodd-Frank Wall Street Reform and Consumer Protection Act. Its primary responsibilities will be to advise the Secretary of the Treasury on insurance issues, consult with the states on insurance matters of national and international importance, and monitor all aspects of the insurance industry. It will also have the authority to identify issues or gaps in the regulation of insurance that could contribute to a systemic crisis and to make recommendations to the Financial Stability Oversight Council as to whether an insurer should be subject to supervision by the Board of Governors of the Federal Reserve. It will also play a substantial role in coordinating federal efforts and policies on international insurance issues.
} 


\section{Evaluation of current practices and potential reforms}

\section{Solvency regulation}

\section{Philosophy and approach}

The approach to overseeing the financial condition and risk of insurance companies should be foremost in any discussion of regulatory policies. One can contrast two basic approaches to insurance solvency regulation: (1) a "prescriptive" or "rulesbased" system; and (2) a "principles-based" system. In the United States, the various states have tended to apply a prescriptive approach to regulating insurers' financial condition that is heavily influenced by an accounting perspective. This is reflected in a voluminous set of laws, regulations, rules and other measures that govern insurers' financial structure and actions. ${ }^{24}$ Regulators have tended to focus on insurers' compliance with these prescriptions rather than the prudence of their management and actions and their overall financial risk.

Unlike the United States, many European countries such as the United Kingdom have employed or are moving towards a principles-based approach to insurance regulation. ${ }^{25}$ In such a system, emphasis is placed on insurers maintaining an adequate "solvency margin" and the competence and judgement of an insurer's management and actions with an insurer's financial risk being the ultimate point of focus for supervisors. Hence, regulators must pay close attention to how well insurers are managed and exercise significant discretion in the actions or interventions they may employ to correct practices or problems as they deem necessary. This approach should allow insurers greater freedom in managing their affairs as long as they use that freedom judiciously, do not engage in excessively hazardous ventures or transactions and ultimately keep their financial risk within reasonable bounds. This philosophy is embodied in the EU's collective insurance solvency initiatives that set common standards for all EU member countries. ${ }^{26}$

Proponents of the prescriptive approach to insurance solvency regulation might argue that it is preferable to have a detailed set of rules to govern an insurer's financial structure and actions for which compliance can be readily determined. Their concern might be that too little emphasis on rules and too much emphasis on principles would give insurance companies too much discretion and some might abuse this discretion and take on excessive risk to the detriment of policy-holders and other creditors. The drawback of such an approach is that it potentially establishes a set of constraints that may not be optimal for a given insurer. Further, regulators are compelled to engage in a torturous process of amending and expanding their rules over time as circumstances change and new sources of financial risk arise.

\footnotetext{
${ }^{24}$ See, for example, Eling et al. (2009) for an assessment and comparison of U.S. and EU insurance financial regulation. Work on Solvency II continues as the European Commission and the European Insurance and the European Insurance and Occupational Pensions Authority (EIOPA) address outstanding issues and finalise the technical specifications that will underlie Solvency II standards and practices. Associated reports and technical documents are available at www.ec.europa.eu/internal_ market/insurance/solvency/index_en.htm and www.eiopa.europa.eu/.

${ }^{25}$ See Tiner (2007).

${ }^{26}$ See Eling et al. (2007) and Elderfield (2009) for a more a detailed review of EU solvency initiatives.
} 
Proponents of a principles-based approach might argue that it gives insurance companies greater flexibility in managing their financial risk according to certain established standards, and regulators can employ greater discretion in taking appropriate actions against insurers that take on excessive financial risk. They might also contend that this approach gives insurance companies greater incentives to manage their financial risk within acceptable parameters and the flexibility to do so. In theory, this approach would seem to be more efficient and properly focused on the overall financial risk of an insurer rather than its mere compliance with an arbitrary set of rules. However, in practice, the success of a principles-based approach depends heavily on the principles and standards that are set and the competence and motivation of regulators to take corrective action when it is warranted. Regulators in the United Kingdom would probably argue that they have met that test, although there have been some criticisms of how its Financial Service Authority has dealt with certain incidents. ${ }^{27}$ As the Solvency II initiative is implemented, there will be an opportunity to see how well a principles-based approach works when it is employed on a wider scale.

It should be noted that regulators in the United States have taken steps in adopting some aspects of a principles-based approach and are increasing their emphasis on financial risk. ${ }^{28,29}$ As this process continues to evolve, insurance regulation in the United States may become a hybrid system that employs both elements of a rulesbased approach and of a principles-based approach one. It will be interesting to see how well such a hybrid system performs compared to other systems.

\section{Capital standards}

Capital requirements constitute the linchpin for the financial regulation of insurance companies as well as banks. The capital requirements for insurance companies can take several forms. Prior to the 1990 s, fixed capital requirements were common. During the past 15 years, most of the major developed economies have moved towards some form of risk-based approach to determining how much capital an insurer is required to hold for regulatory purposes. ${ }^{30,31}$ Using this approach, the regulatory capital requirements may be determined by simple or complex formulas or the use of internal or standard models.

In the United States, insurers are subject to fixed capital requirements set by each state as well as uniform risk-based capital (RBC) standards based on complex formulas promulgated by the NAIC that have been adopted by every state. ${ }^{32}$ There are different formulas for property-casualty, health and life insurance companies. In $\mathrm{RBC}$ formulas, selected factors are multiplied times various accounting values

\footnotetext{
${ }^{27}$ See, for example, European Parliament (2007).

${ }^{28}$ Vaughan (2009).

${ }^{29}$ Vaughan argues that "the optimal structure of insurance supervision is likely to be a combination of a rules-based and principles-based approach".

${ }^{30}$ ChandraShekar and Warrier (2007), Eling et al. (2009).

${ }^{31}$ Also see Holzmüller (2009) for a comparison and critique of capital standards in the United States and European Union (Solvency II).

${ }^{32}$ An insurer is required to have capital that meets or exceeds the higher of the two standards.
} 
186

(e.g., assets, liabilities or premiums) to produce RBC charges or amounts for each item. The charges are summed into several "baskets" and then subjected to a covariance adjustment to reflect the assumed independence of certain risks. An insurer's calculated RBC amount is compared to its actual total adjusted capital (TAC) to determine its RBC position. Certain company and regulatory actions are required if a company's TAC falls below a certain level of RBC. Four RBC levels for company and regulatory action have been established, with more severe action required for companies as they reach lower levels.

Arguably, the U.S. approach to determining RBC requirements reflects both the heights and the limits to what can be achieved with a formula-based method. When first adopted, the U.S. system was considered relatively advanced when compared with how regulatory capital requirements were determined in other countries and a significant improvement over fixed capital requirements. However, over time, using static formulas to determine how much capital an insurer hold seems increasingly antiquated in light of the advances that have occurred in dynamic financial analysis (DFA) and the use of models to assess and manage insurers' financial risk. ${ }^{33}$ In addition, accounting values can either be erroneous or manipulated to obtain more favourable regulatory assessments. For example, Cummins et al. ${ }^{10}$ observe that the property-casualty formula encourages insurers to lower their loss reserves to reduce the associated RBC charge.

Further, while not all risks can be quantified, the U.S. RBC formula omits some that can be, such as operational risks, using methodological tools now available. It is also important to note that the U.S. RBC formula contains no explicit adjustment for an insurer's size or its catastrophe exposure. ${ }^{34}$ Factors for both were proposed in the initial development of the property-casualty $\mathrm{RBC}$ formula but were rejected. The NAIC is currently considering adding a catastrophe component to RBC for propertycasualty insurers, but this initiative is bogged down in a debate that is unlikely to be resolved any time soon.

When the EU embarked on its mission to develop a common set of capital standards under its Solvency II initiative, it was positioned to take advantage of the advances in risk analysis and modelling that have occurred. The primary goal of Solvency II is to develop and implement harmonised RBC standards across the EU. The intent is to take an enterprise risk-management (ERM) approach towards capital standards that will provide an integrated solvency framework that covers all significant risk categories and their interdependencies.

Solvency II consists of three pillars: (1) quantitative requirements, (2) qualitative requirements and supervision, and (3) supervisory reporting and public disclosure. The quantitative requirements under Pillar 1 include the valuation of assets and

${ }^{33}$ In 2000, the NAIC introduced a model-based component to assess the interest rate risk associated for fixed annuities. In 2005, this approach was extended to assess the market risk, interest rate and expenserecovery risk of variable annuities.

${ }^{34}$ Based on the current formulas, an insurer's RBC requirement increases proportionately with the amount of its premiums, assets and loss reserves. However, arguably, according to the "law of large numbers", an insurer's risk does not increase proportionately with its size. With a size adjustment, a small insurer would have a higher relative $\mathrm{RBC}$ requirement than a large insurer, all other things equal. 
liabilities, technical provisions, own funds, regulatory capital requirements and investments employing a total balance sheet approach with market-consistent valuation of assets and liabilities. There will be two levels of regulatory capital requirements. The first level is the minimum capital requirement (MCR), which is the minimum amount of equity capital that an insurer must hold. An insurer that failed to meet its MCR would be subject to immediate regulatory intervention. The second level is the solvency capital requirement (SCR), also called "target capital", which is intended to represent the economic capital an insurers needs to conduct its business within a given safety level. In determining SCR, all significant risk categories are covered, including insurance, market, credit and operational risk. Furthermore, risk mitigation techniques applied by insurers (such as reinsurance and securitisation) are considered. An insurer that falls between its MCR and SCR may be subject to regulatory action based on regulators' determination of whether corrective steps are warranted. MCR will be a fraction of SCR, although the precise value has yet to be determined.

EU regulators are considering the use of both standard and internal models to calculate MCR and SCR. The advantage of a standard model is that it may be less burdensome for insurers because it will not require them to invest the resources that would be needed to develop an internal model that would be specific to each firm. An internal model would be developed by an insurer to better fit its particular circumstances and needs subject to certain parameters established by regulators. Large insurers will probably be more likely to opt for an internal model while small and medium-sized insurers may be more likely to adopt a standard model because of resource considerations. It should be noted that an insurer will need regulatory approval to be allowed to use an internal model to determine its capital requirements.

A model-based approach to determining regulatory capital requirements for insurance companies has the potential of being superior to a formula-based approach. A model-based approach has the desirable attributes of compelling insurers to take a more forward-looking and comprehensive view of their financial risk and determining a regulatory capital amount that is better tailored to fit a particular insurer's specific needs and circumstances. Many large insurers are already performing capital modelling and incorporating ERM practices in their risk management activities. Hence, a model-based approach would seem most consistent with the regulatory goal of employing best practices to ensure that regulatory policies and standards are effective and efficient.

At the same time, this argument has some qualifiers. Even the most sophisticated approaches to capital modelling are imperfect and their performance is dependent on a number of factors including model inputs and assumptions. ${ }^{1,35}$ Further, compelling insurers to use models to determine their capital requirements will require them to invest in additional resources that could be costly, especially for insurers who are not

\footnotetext{
${ }^{35}$ Vaughan (2009) asserts that internal models should be an adjunct to a rules-based capital requirement that establishes a floor for the amount of capital that an insurer would be required to hold for regulatory purposes.
} 
currently using capital models. In addition, a model-based approach places additional demands on regulators in terms of developing reasonable standards and evaluating insurers' model results. Sceptics might argue that some insurers that would be allowed to use internal models might use this freedom to "game the system" and take on excessive risk. Finally, there is the risk that regulators will rely too heavily on capital requirements and not give adequate attention to other components of a sound and comprehensive financial regulatory system.

It also should be noted that while many analysts view that the approach to setting capital standards in the EU's Solvency II initiative is superior to the current U.S. RBC formulas, the EU approach is not immune to criticism. Holzmüller ${ }^{36}$ compared and evaluated U.S. RBC, Solvency II and the Swiss Solvency Test based on 11 criteria. She concluded that U.S. RBC only partially satisfied three of the criteria and that Solvency II fully satisfied three of the criteria and partially satisfied the remaining eight criteria. With respect to Solvency II, she highlighted concerns with respect to factor-based calculations within parts of the standard approach (model), the use of the value-at-risk concept, which does not incorporate the distribution of costs in the event of insolvency, and inadequate consideration of management risk.

\section{Investments}

Insurers must properly manage their investments (i.e., assets) to support their obligations to policy-holders. This involves a proper balance of risk and return consistent with the mission and appropriate risk profile of an insurance company. While capital requirements consider the risk embedded in an insurer's asset portfolio, it is prudent for regulators to take additional steps to ensure that insurers are properly managing their investments and are not overly invested in high-risk assets.

The regulation of investments can take two forms that are not mutually exclusive. One approach is to promulgate a set of rules and constraints that deter an insurer from investing too heavily in high-risk assets. A second approach is to require insurers to develop and implement prudent investment policies. One can see both approaches in U.S. regulations governing insurers' investments.

The NAIC has several model laws/regulations that pertain specifically to investments. One is the Investments of Insurers Model Act (Defined Limits Version). A second is the Investments of Insurers Model Act (Defined Standards Version). The latter is intended to take more of a prudential and principles-based approach to regulating insurers investments while the former is more rules-based or prescriptive in terms of setting specific limits and other rules that govern insurers' investments.

Both model laws contain provisions concerning insurance company practices in managing its investment portfolio. For example, they require that an insurer's board of directors adopt a written plan for acquiring and holding investments and related activities. The model acts further stipulate procedures that the board of directors should follow in managing an insurer's portfolio.

The defined limits model act contains several provisions that are illustrative of a prescriptive approach. Specifically, it prohibits a life insurer from holding more

\footnotetext{
${ }^{36}$ Holzmüller (2009).
} 
than 20 per cent of its admitted assets in medium and lower grade investments with a 10 per cent limit for lower grade investments, a 3 per cent limit for Securities Valuation Office Class 5-6 investments and a 1 per cent limit for Class 6 investments. There are other provisions that set rules and limits with respect to mortgage loans and real estate. Investments in derivatives for "income generation" are limited to 10 per cent of a life insurer's admitted assets (the limit for propertyliability insurers is 7.5 per cent).

The defined standards model act contains fewer specified limits and more provisions concerning how an insurer is expected to manage its investments and the associated risks. Similar to the defined limits act, it stipulates the role and responsibilities of the board of directors in managing an insurer's investments "prudently". It goes on to list "prudence evaluation criteria" that regulators may consider in assessing the adequacy of an insurer's investment management. Interestingly, these criteria include "systemic risk". It also provides for a "minimum financial security benchmark" (MFSB) that authorises regulators to require an insurer to hold more capital than that required under RBC and fixed minimum capital standards. It also sets a "minimum asset requirement", which is the sum of MFSB and an insurer's liabilities. Additionally, it contains limits for specified asset classes that in some cases are the same as in the defined limits act and in other cases appear to be more liberal. The model act does not appear to impose a specific limit on derivative investments other than those implicitly contained in other provisions.

As noted above, those insurers that have been subject to a limit on their holdings of derivative instruments for income generation purposes (either by New York or other states) may have ultimately benefitted from this constraint if it prevented them from investing more heavily in assets exposed to the implosion of the housing market. Looking forward, U.S. regulators may contemplate even stricter limits tied to the type of collateral underlying asset-backed securities. Some may view this as being a more reliable approach than promulgating general principles and standards that further guide an insurer's investments in these securities. Of course, these approaches are not mutually exclusive and both could be included in revised investment regulations. Regardless, U.S. regulators need to revisit their supervision of insurers' investment practices in line with the lessons learned from the most recent crisis.

One problem revealed by recent events was over-reliance on credit rating agencies' assessment of the default risk associated with mortgage-backed and asset-backed securities. Many of the securities backed by subprime mortgages were given investment-grade ratings despite the much higher risk associated with these securities. This underlies the need for regulators and insurers to undertake their own assessment of the risks associated with these types of securities. Regulators should take the initiative and "reclassify" investments as to their credit quality if the rating agencies have underestimated their default risk. This kind of initiative has implications beyond the regulation of investments per se, as the reclassification of the credit quality of certain assets would also affect the capital requirements for an insurer and financial monitoring systems.

Under Pillar 1 of the Solvency II directive, quantitative investment limits and asset eligibility will be eliminated. The rationale given for this step is threefold: (1) the new 
valuation standards take due account of the credit and liquidity characteristics of assets; (2) SCR captures all quantifiable risks; and (3) all investments are subject to the "prudent person" principle. If new risks emerge that are not covered by SCR, the European Commission has the authority to adopt temporary investment limits and asset liability criteria while the standard formula is being updated. The elimination of investment restrictions would likely be considered a bold step by U.S. regulators. Critics of such a policy might argue that it relies too heavily on capital models and regulators' enforcement of "prudent person" principles.

\section{Financial reporting and monitoring}

The monitoring of insurers' financial condition and risk should be an important component of any regulatory system. It is essential to ensure that insurers are complying with the principles, standards and rules that have been promulgated by regulators and that regulators take prompt corrective actions against insurers that incur excessive financial risk or are in financial distress.

Financial monitoring encompasses a broad range of regulatory activities, including financial reporting, early-warning systems, financial analysis, examinations and other measures intended to assess an insurers' financial condition and the management of its financial risk. ${ }^{37}$ In the United States, insurers file annual and quarterly financial statements, which serve as the principal sources of information for the solvency monitoring process, but a number of other special reports are filed and used in regulatory monitoring. Accounting rules take on added importance because accounting values become the principle measures that determine whether an insurer is complying with regulatory standards. ${ }^{38}$ Regulators also have broad authority to compel insurers to provide other information deemed necessary to assess their financial condition.

U.S. regulators subject the reports filed by insurers to a "bench" or "desk" audit by an in-house financial analyst or examiner who assesses the information's accuracy and reasonableness and determines whether an insurer requires further investigation. Typically, an insurer's domiciliary regulator performs the most extensive review of its financial information, but an insurer must file financial reports with every state where it is licensed, and non-domiciliary regulators also may review these reports. Additionally, the NAIC scrutinises insurers' financial statements and disseminates its analysis to state insurance departments. This reflects the multilayered nature of financial regulation and monitoring of U.S. insurers - the domiciliary regulator constitutes the first layer, and non-domiciliary regulators and the NAIC constitute successive layers. Some might question whether this multilayered regulation and monitoring is redundant, but in the U.S. system it is viewed as essential to assure that domiciliary regulators are taking appropriate actions against insurers in financial distress.

\footnotetext{
${ }^{37}$ See Klein (2009) for a more detailed discussion of the financial monitoring of insurance companies in the United States.

${ }^{38}$ In the United States, insurance companies are subject to Statutory Accounting Principles that are consistent with GAAP in many areas but differ in some respects.
} 
State regulators rely heavily on early-warning systems and other financial analysis tools in their monitoring activities. The fact that U.S. RBC standards are relatively low makes financial monitoring particularly important because an insurer could be in financial distress and still exceed its RBC requirement. For the most part, these systems and tools are based on static, quantitative financial ratios. There is some use of qualitative information, but this appears to be limited and also may vary among the different states. Two principal early warning systems are employed in the United States: the Insurance Regulatory Information System (IRIS) and the Financial Analysis Solvency Tools (FAST) system. IRIS comprises 12-13 financial ratios (depending on the type of insurer), and its results are made available to the public. Normal ranges are set for each ratio. Ratio results that fall outside these ranges and other criteria can trigger further regulatory investigation.

In the early 1990s, U.S. regulators concluded that IRIS was inadequate, which led to the development of the FAST system. In the NAIC's explanation of its systems, FAST comprises the full array of its solvency monitoring tools (including IRIS), but its heart is a computerised analytical routine called the "scoring system". The scoring system consists of a series of approximately 20 financial ratios based on annual and quarterly statement data, but, unlike the IRIS ratios, it assigns different point values for different ranges of ratio results. A cumulative score is derived for each company, which is used to prioritise it for further analysis. These scores are provided to all regulators but are not available to the public.

U.S. regulators use additional tools and information in their financial monitoring activities. They can use the NAIC's "Insurer Profiles System" and may also develop their own customised financial ratios. Both periodic (every three to five years) and targeted company financial examinations are conducted; targeted exams are performed to address specific questions or concerns that arise from bench audits and analysis. Additional sources of information may be tapped, including Securities and Exchange Commission filings, claims-paying ability ratings, complaint ratios, market conduct reports, correspondence from competitors and agents, news articles, and other sources of anecdotal information. While a wide array of information sources are available, it appears that U.S. regulators rely primarily on quantitative data and tools, as well as financial examinations. This is consistent with a prescriptive, rulesbased approach as most rules are stated in quantitative terms. Importantly, U.S. regulators tend not to engage in consultations with an insurance company's management to assess its competence and future plans.

Only three studies have tested the "predictive accuracy" of both the IRIS and FAST systems. Prediction refers to the ability of these systems to identify insurers that ultimately fail (are seized by regulators) and those that do not. These studies also have included insurers' RBC ratio (i.e., the ratio of Total Adjusted Capital to the Authorised Control Level RBC amount) as an additional explanatory variable, although insolvency prediction is not its purpose. These studies have generally found that the IRIS/FAST systems are reasonably effective in the sense that they contribute significantly to models designed to predict insurer failures. At the same time, these studies have found that these systems could be improved by recalibrating the FAST scoring model and adding more variables and components to these systems, including financial strength ratings and some form of cash flow 
192

testing. ${ }^{39,40}$ It should be noted that these studies judge the NAIC early warning systems by past performance. Hence, they cannot assess their effectiveness based on new problems or risks that are not reflected in the sample data periods used.

The cash flow simulation used by Cummins et al. ${ }^{39}$ comes closest to employing some form of DFA in early warning systems; its significant explanatory power in insolvency prediction tests lends support to its consideration in determining capital adequacy and financial monitoring. It is difficult to estimate the effect of using more qualitative methods and information, as these things do not lend themselves as easily to empirical testing. The predictive value of claims-paying ability ratings comes closest to indicating the potential contribution of qualitative analysis, which is a part of the rating process.

This brings us to the issue of how existing monitoring systems detect the kinds of problems or risks that insurers are now encountering. As discussed above, the IRIS and FAST systems use relatively broad indicators that tend to lag behind actual events. Arguably, a number of these measures address areas generally relevant to the financial crisis but none specifically focus on the most relevant items. For example, both systems contain measures of capital adequacy, leverage, financial performance and investments. The ratio of non-investment grade bonds to assets and investment yield are used to identify concentrations of high-risk assets. However, these measures only crudely indicate insurers' exposures to losses from mortgage-backed securities or subprime mortgages. If insurers' reporting requirements are enhanced to provide better information on the credit quality of their assets, the additional data could be used to improve early warning systems.

Regulators may modify or add measures in an effort to fill this gap. Essentially, any figures reported by insurers are fair game in terms of developing new financial structure/risk measures. Because it is a public system, changes to IRIS tend to occur less frequently. In contrast, because FAST is not public, regulators are able to modify it more easily and frequently. Looking more broadly, other methods used for analysing insurers' financial risk offer additional opportunities for risk assessment. For example, stress testing of life insurers' policy reserves could be expanded to other areas and risk exposures. Further improvements in the financial monitoring systems used by U.S. regulators are warranted if this component of solvency regulation is to adhere to the principle that regulators should employ the most efficient and effective means to remedy market failures.

It should be noted that the NAIC acknowledges some of these deficiencies and is taking steps to address them. For example, in 2004 it adopted the Risk-Focused Surveillance Framework, which has four components: (1) risk-focused exams; (2) offsite risk-focused financial analysis; (3) examination of internal and external changes in the organisation; and, (4) an annual supervisory plan for each insurer developed by its domiciliary regulator. ${ }^{41}$ While this initiative is laudable in concept, it is difficult for external observers to assess its success. Arguably, it would constitute a significant shift

\footnotetext{
${ }^{39}$ Cummins et al. (1999).

${ }^{40}$ Pottier and Sommer (2002).

${ }^{41}$ See Vaughan (2009) for more discussion of this initiative.
} 
from the paradigm that has characterised the U.S. approach to financial surveillance historically. With time and strong encouragement by the NAIC, its objectives may be fully realised as regulators develop the capacity and mindset necessary for this to happen.

The NAIC is considering other initiatives that might be encompassed under the broad definition of financial monitoring. One of these initiatives would be the introduction of something akin to the Own Risk and Solvency Assessment that is an element of Pillar 2 under Solvency II. Another initiative is to increase the focus on corporate governance. These would be significant enhancements to U.S. financial monitoring and could substantially increase the use of qualitative methods to assess how well an insurer is managing its financial risk.

\section{Intervention}

Intervention might be viewed as the final step in the regulatory process. Intervention could be broadly defined as any specific action by regulators to force an insurer to alter its behaviour, transactions or structure. This could mean bringing an insurer into compliance with existing regulations or going beyond regulations to achieve some desired outcome.

There are two categories of regulatory actions with respect to troubled companies in the United States: (1) actions to prevent a financially troubled insurer from becoming insolvent; and (2) delinquency proceedings against an insurer for the purpose of conserving, rehabilitating, reorganising or liquidating the company. Some of these actions may be conducted informally; others require formal measures. Similarly, some actions against companies may be confidential, and others may be publicly announced. Regulators can negotiate sales or mergers of troubled insurers in order to avoid market disruptions. This is often more feasible for life-health insurers because of the embedded value of their long-term contracts.

If preventive regulatory actions are too late or are otherwise unsuccessful and an insurer becomes severely impaired or insolvent, then formal delinquency proceedings will be instituted. These measures can encompass conservation, seizure of assets, rehabilitation, liquidation and dissolution. For many insurers, these actions are progressive. A regulator may first seek to conserve and rehabilitate a company to maintain availability of coverage and to avoid adverse effects on policy-holders and claimants, as well as lower insolvency costs. The regulator, however, ultimately may be forced to liquidate and dissolve the company if rehabilitation does not prove to be feasible. This is often the case with property-casualty insurers that have already dug themselves into a deep hole by the time regulators seize control.

One question that is difficult to answer is how much leverage regulators can exercise in compelling an insurer to lower its financial risk if it greatly exceeds its regulatory capital requirement and complies with all regulations from a quantitative perspective. In theory, U.S. regulators can act against any company deemed to be in "hazardous financial condition". However, regulators would bear the burden of proof if an insurer resisted corrective action that ultimately would have to be resolved in court. In practice, when regulators initiate formal actions, an insurer's problems are sufficiently obvious that the courts typically approve such actions. What we cannot observe is 
regulators' power and inclination to impose their will in informal actions that are not subject to public disclosure.

This brings us back to the orientation of regulators and their authority. A greater reliance on rules rather than principles may cause regulators to refrain from actions that go beyond enforcing compliance with specific regulations. In a principles-based system guided by a prudential philosophy, regulators may exercise greater discretion and take actions whenever they believe a company is not properly managing its financial risk. U.S. regulators may believe that they can exercise this kind of discretion if they choose to do so. The questions lie both with their authority and inclinations.

This discussion has some bearing on the role that regulation can play in mitigating insurers' vulnerability to systemic risk. To the extent that existing or new regulations fail to prevent an insurer from incurring excessive financial risk in its investment decisions, then regulatory discretion could become a key factor. If regulators are authorised and inclined to constrain what they consider to be imprudent or risky behaviour, this could strengthen regulatory enforcement of company risk management practices and reduce their vulnerability to systemic risk. However, some insurers may oppose such regulatory discretion, especially if it is not governed by guiding principles and standards. This issue warrants consideration in contemplating changes to the U.S. regulatory system and how rules and principles will be used.

\section{Price regulation}

Price or rate regulation is the second area that deserves some discussion. In the United States, the extent and stringency of rate regulation varies significantly by line and by state. The lines subject to the greatest rate regulation are personal auto, homeowners, workers' compensation and health insurance. The reality is that in most states and markets, at a given point in time, regulators do not attempt to impose severe price constraints. The problem arises when strong cost pressures compel insurers to raise their prices and regulators resist market forces in an ill-fated attempt to ease the impact on consumers. ${ }^{42}$ Inevitably, severe market distortions occur. Ultimately, insurance markets can be sucked into a "downward spiral" as the supply of private insurance evaporates and state mechanisms are forced to cover the gap. Rate suppression also can decrease incentives to reduce risk that can lead to rising claim costs that further increases pricing and market pressures. Together, these developments can create major crises in the cost and supply of insurance.

One example of where rate regulation has gone awry is homeowners insurance in Florida where this is a substantial exposure to hurricanes. Florida regulators have imposed tight constraints on homeowners insurance rates since Hurricane Andrew struck the state in 1992. As a consequence, many large national insurers have exited the market or substantially reduced the amount of homeowners insurance they write.

\footnotetext{
${ }^{42}$ Regulators may seek to suppress overall rate levels and/or compress rate differentials between low and high-risk insureds.
} 
They have been replaced by a large number of small, single-state or regional insurers with most of their exposures concentrated in Florida. The number of policies in the residual market for property insurance (the Citizens Property Insurance Corporation) has grown from approximately 400,000 in 1993 to more than 1.3 million in March 2011.

The argument for rate deregulation is fairly straightforward. One would expect that prices in competitive insurance markets would be "actuarially fair" and not excessive. In addition, competition should drive insurers to be efficient and prices should gravitate to the lowest possible level necessary to cover the cost of an efficient insurer, including its cost of capital or a "fair" profit. If one accepts the notion that competitive prices are desirable and insurers will charge such prices in the absence of government intervention, then there is no need for rate regulation if insurance markets are competitive. The empirical research overwhelmingly confirms both the competitive nature of insurance markets and the lack of benefits from rate regulation as discussed in the section "Economic principles for insurance regulation". Requiring or authorising regulators to regulate rates invites political pressure and interference that can lead to the dismal scenario described above. Hence, the further deregulation of insurance pricing in the United States seems warranted and would enable regulators to allocate more resources to address true market failures.

Rate regulation was common in the EU until 1994 when it was essentially eliminated with the introduction of the Third Generation Insurance Directive. Some member countries, however, still regulate other factors that indirectly affect insurance prices. An example is the automobile insurance bonus-malus system in France. ${ }^{43}$ While auto insurance rates are not explicitly regulated, the premiums are adjusted by a bonusmalus coefficient (set by law) that considers a driver's past experience. This type of regulation of rating factors may be less intrusive than full price regulation, but one might question if it is really necessary in competitive insurance markets. Nonetheless, the EU appears to have moved closer to the desirable goal of full price deregulation than the United States.

\section{Market conduct}

As discussed in the section "Economic principles for insurance regulation", a stronger case can be made for some regulation of market conduct in insurance that involves both insurance companies and their intermediaries. In the United States, the concern lies less with the scope of market conduct regulation and more with the methods used to regulate market conduct. Currently, the states subject insurers to extensive, duplicative and costly examinations that focus too much on minor errors and too little on major patterns of abuse. In other words, regulators "miss the forest for the trees". Regulators also fail to recognise and encourage insurer self-compliance efforts. Klein and Schacht $^{44}$ discuss the problems with the current system and suggest a more effective and efficient approach to market conduct monitoring that would maximise

\footnotetext{
${ }^{43}$ Dionne (2001).

${ }^{44}$ Klein and Schacht (2001).
} 
reliance on self-regulatory mechanisms and target regulatory investigation and enforcement to significant problems.

\section{Summary and conclusions}

An effective and efficient regulatory system for insurance should be guided by a set of principles that are well grounded in economic theory. The economic foundation for regulation is based on the presence of market failures. The market failures that are most evident in insurance include severe asymmetric information problems and principal-agent conflicts that could lead some insurance companies to incur excessive financial risk and/or engage in abusive market practices that harm consumers. Insurance consumers, particularly individuals and households, face significant challenges in judging the financial risk of insurers and properly understanding the terms of insurance contracts.

These types of market failures support an argument for regulating insurers' financial condition and some aspects of their market conduct. With respect to solvency, regulators should seek to prevent insurers from incurring excessive financial risk and limit the cost of insurer insolvencies. As for market conduct, regulators should take steps to discourage and sanction insurers and intermediaries that take unfair advantage of consumers, such as misrepresenting the terms of insurance contracts and failing to pay legitimate claims. There appears to be little justification for the regulation of insurance prices in competitive markets in which entry/exit barriers are low or non-existent.

However, not all market failures can necessarily be corrected by regulation so that the end result will be an increase in social welfare. The desirability of any particular regulatory intervention must be assessed in terms of regulators' ability to remedy a specified market failure and any deadweight costs associated with regulatory intervention that may exceed the benefits from intervention. Further, regulators should employ "best practices" and the most efficient measures to address market failures. Ultimately, regulators have to balance the benefits and costs of specific regulatory policies and methods to maximise the net gains from any regulatory intervention. Applying these principles in evaluating current regulatory practices leads to the following conclusions.

Both the United States and the EU have fairly robust systems for regulating the financial condition of insurance companies, although they differ in philosophy and approach. Financial regulation in the United States could be improved by adopting more advanced methods. The EU Solvency II initiative embraces more advanced methods and has the potential for creating a more effective and efficient system for regulating insurer solvency. Its success in this endeavour will be determined as it reaches the implementation stage and all the necessary components for a comprehensive regulatory scheme are developed.

It is unlikely that the United States will adopt the kind or regulatory system envisioned in Solvency II in the foreseeable future but there are specific improvements that could be made that are politically feasible. First, U.S. regulators should critically review its prescriptive requirements and consider where it can adopt more principles-based 
standards that will not compromise the goal of preventing insurers from incurring excessive risk. The NAIC has indicated a willingness to consider adopting more principles in its regulatory scheme; the issue lies with how fast and far it is willing to go. Regulatory reform in the United States has always been an incremental process and it will need to move forward with "all deliberate speed" if U.S. regulation is going to keep pace with the reforms in other advanced economies.

The United States also needs to significantly revamp its capital standards. As a first step, it needs to update the parameters of its RBC formulas and incorporate elements for catastrophe risk and operational risk. The NAIC also needs to push ahead with its efforts to use models in assessing capital adequacy. Acknowledging that U.S. regulators are uncomfortable with the full-scale replacement of the existing $\mathrm{RBC}$ formulas with standard or internal models there are other things that could be done. Specifically, the NAIC could develop and test a standard model as an adjunct to its formula-based capital requirements. Standard model results could be used, along with company internal model results, in financial monitoring. Used in this way, regulators would not be bound by model outcomes for determining whether an insurer has adequate regulatory capital but could use model results to help identify high-risk insurers.

In the area of investments and financial monitoring, U.S. regulators need to fully embrace and implement a risk-based approach to assessing insurers' financial condition. They should also increase their use of qualitative methods to evaluate corporate governance and how well an insurer is managing its financial risk. An overarching goal of these kinds of initiatives is to encourage insurers to employ good risk management practices. With respect to investments, regulators need to revisit investment limits, prudential standards and the reliance on rating agencies for determining the credit quality of derivative instruments such as mortgage-backed securities.

The states also should deregulate pricing in all competitive markets. This will be a formidable goal as many states believe price regulation is warranted or are under significant political pressure to constrain rate levels and rating factors. The NAIC could play a greater leadership role in this effort by strongly encouraging price deregulation and advocating its benefits.

With respect to market conduct, a good argument can be made for regulatory intervention to prevent insurers and agents from engaging in unfair practices that harm consumers. However, the form in which market conducts regulation must be efficient. Specifically, regulators should avoid excessive reliance on costly and duplicative market conduct exams that focus too much on findings and penalising minor errors. Instead, regulators should focus on detecting major patterns of abuse and outright fraud. They should also encourage and reward self-compliance efforts by insurers.

\section{References}

Brown, J.R. and Goolsbee, A. (2002) 'Does the internet make markets more competitive? Evidence from the life insurance industry', Journal of Political Economy 110(3): 481-507.

ChandraShekkar, P. and Warrier, S.R. (2007) 'Risk-based capital management: A "principles based approach" to insurer solvency management', Presented at the Asia-Pacific Risk and Insurance Association Annual Conference, 29 May 2007. 
Cummins, J.D. and Weiss, M.A. (1991) 'The structure, conduct, and regulation of the property-liability insurance industry', Federal Reserve Bank of Boston Conference Series, pp. 117-164.

Cummins, J.D., Grace, M.F. and Phillips, R.D. (1999) 'Regulatory solvency prediction in property-liability insurance: Risk-based capital, audit ratios, and cash flow simulation', Journal of Risk and Insurance 66(3): $417-458$.

Cummins, J.D., Harrington, S.E. and Klein, R.W. (1995) 'Insolvency experience, risk-based capital, and prompt corrective action in property-liability insurance', Journal of Banking \& Finance 19(3-4): $511-527$.

Dionne, G. (2001) Commitment and automobile insurance regulation in France, Quebec and Japan, Working paper, HEC Montreal.

Elderfield, M. (2009) 'Solvency II: Setting the Pace for regulatory change', The Geneva Papers on Risk and Insurance-Issues and Practice 34(1): 35-41.

Eling, M., Klein, R.W. and Schmit, J.T. (2009) A Comparison of Insurance Regulation in the United States and the European Union, Policy Report, Oakland, CA: The Independent Institute.

Eling, M., Schmeiser, H. and Schmit, J.T. (2007) 'The Solvency II process: Overview and critical analysis', Risk Management \& Insurance Review 10(1): 69-85.

European Commission (2008) 'Amended Proposal for a Directive of the European Parliament and of the Council on the Taking-Up and Pursuit of the Business of Insurance and Reinsurance (Solvency II)', COM (2008), from http://ec.europa.eu/internal_market/insurance/docs/solvency/proposal_en.pdf.

European Insurance and Occupational Pensions Authority (2011) 'EIOPA Report on the Fifth Quantitative Impact Study (QIS5) for Solvency II', EIOPA-TFQISS-11/001, March 2011, from https://eiopa.europa.eu/ fileadmin/tx_dam/files/publications/reports/QIS5_Report_Final.pdf.

European Parliament (2007) Final Report of the European Parliament's Inquiry into the Crisis of the Equitable Life Assurance Society, 25 May.

Grace, M.F. and Klein, R.W. (2007) The Effects of an Optional Federal Charter on Competition in the Life Insurance Industry, Report to the American Council of Life Insurance, Washington, D.C.

Grace, M.F. and Klein, R.W. (2008) Understanding Property-Casualty Insurance Profits: The Importance of Financial Strength, Report to the Insurance Information Institute and the American Insurance Association, Washington, D.C.

Grace, M.F. and Klein, R.W. (eds.) (2009) The Future of Insurance Regulation, Washington, D.C.: Brookings Institution Press.

Hanson, J.S., Dineen, R.E. and Johnson, M.B. (1974) Monitoring Competition: A Means of Regulating the Property and Liability Insurance Business, Milwaukee, WI: National Association of Insurance Commissioners.

Harrington, S.E. (1992) 'Rate suppression', Journal of Risk and Insurance 59(2): 185-202.

Harrington, S.E. (2002) 'Effects of prior approval rate regulation of auto insurance', in J.D. Cummins (ed.) Deregulating Property-Liability Insurance: Restoring Competition and Increasing Market Efficiency, Washington, D.C.: AEI-Brookings Joint Center for Regulatory Studies.

Holzmüller, I. (2009) 'The United States RBC standards, Solvency II and the Swiss solvency test: A comparative assessment', The Geneva Papers on Risk and Insurance-Issues and Practice 34(1): 56-77.

Insurance Information Institute (2011) The Fact Book 2011, Washington, D.C.: Insurance Information Institute.

Joskow, P.L. (1973) 'Cartels, competition and regulation in the property-liability insurance industry', The Bell Journal of Economics and Management Science 4(2): 375-427.

Klein, R.W. (1995) 'Insurance regulation in transition', Journal of Risk and Insurance 62: 263-404, 93.

Klein, R.W. (2005) A Regulator's Introduction to the Insurance Industry, $2^{\text {nd }}$ edn. Kansas City, MO: National Association of Insurance Commissioners.

Klein, R.W. (2009) 'The future of the financial monitoring of insurance companies in the U.S', Journal of Insurance Regulation 28: 73-78.

Klein, R.W. and Schacht, J. (2001) 'An assessment of insurance market conduct surveillance', Journal of Insurance Regulation 20: 51-93.

Munch, P. and Smallwood, D.E. (1981) 'Theory of solvency regulation in the property and casualty insurance industry', in G. Fromm (ed.) Studies in Public Regulation, Cambridge, MA: MIT Press.

National Association of Insurance Commissioners (2011) Issue Brief: Health Insurance Rate Regulation, Washington, D.C.: National Association of Insurance Commissioners. 
Pottier, S. and Sommer, D. (2002) 'The effectiveness of public and private sector summary risk measures in predicting insurer insolvencies', Journal of Financial Services Research 21(1): 101-116.

Pottier, S. (2011) 'Life insurer efficiency and state regulation: evidence of optimal firm behavior', Journal of Regulatory Economics 39(2): 169-193.

Scherer, F.M. and Ross, D.S. (1990) Industrial Market Structure and Economic Performance, $3^{\text {rd }}$ edn. Boston, MA: Houghton-Mifflin.

Spulber, D.F. (1989) Regulation and Markets, Cambridge, MA: MIT Press.

Swiss Re (2010) Sigma No. 3/2010: Regulatory Issues in Insurance, from http:/www.swissre.com/sigma/, accessed 25 January 2011.

Tiner, J. (2007) Principles-based regulation-Looking to the future, Speech at the FSA Insurance Sector Conference, 21 March.

Vaughan, T.M. (2009) 'The Implications of Solvency II for U.S. Insurance Regulation', Networks Financial Institute Policy Brief, Indiana State University.

Viscusi, W.K., Harrington, J.E. and Vernon, J.M. (2000) Economics of Regulation and Antitrust, 3rd edn. Boston, MA: MIT Press.

Wang, S., Klein, R., Ma, G., Wei, X. and Zanjani, G. (2009) The Financial Crisis and Lessons for Insurers, Report to the Society of Actuaries, September.

\begin{abstract}
About the Author
Robert W. Klein is Director of the Center for Risk Management and Insurance Research and an Associate Professor of Risk Management and Insurance at Georgia State University in Atlanta. He has over 30 years of experience as a regulator and an academic researcher in the areas of insurance markets, insurance regulation and public policy. He has a doctoral degree in Economics from Michigan State University.
\end{abstract}

